\title{
Variables that influence the healing at implants installed immediately after extraction
}

\author{
Iida $T^{1,2}$, Kawakami $\mathrm{S}^{1,2}$, Botticelli $\mathrm{D}^{2 *}$, Apaza Alccayhuaman $\mathrm{KA}^{2}$ and Omori $\mathrm{Y}^{1,2}$ \\ ${ }^{1}$ Osaka Dental University, Osaka, Japan \\ ${ }^{2}$ ARDEC Academy, Rimini, Italy
}

\begin{abstract}
Several variables may influence the healing at implants installed immediately after tooth extraction. The position and dimensions of the implants in relation to the extraction sockets, the use of alveolar preservation or regenerative techniques, the presence of neighbor teeth are altogether conditions that will influence the outcome at implants installed immediately after tooth extraction. All these aspects are analyzed in the present article.
\end{abstract}

Several variables may influence the outcomes of implants installed immediately in an extraction socket. A volumetric reduction of the alveolar crest will always occur after tooth extraction, as a physiologic result of the loss of the volume occupied by the teeth and the loss of the periodontal ligament that was supporting buccal crest. The extents of this shrinkage have been reported in various studies. In one study on 149 cast models [1], the dimensions at edentulous sites were compared with those at the contralateral site where the teeth were still present. A reduction of 3.5-3.6 $\mathrm{mm}$ at the buccal aspect, and 1.7 to $2.0 \mathrm{~mm}$ at the lingual aspect was found at the extraction sites compared to the dentate zones. In a clinical study, 46 patients were followed for one year after tooth extraction [2] and clinical measurements, $\mathrm{x}$-rays and cast models were taken before extraction and after various periods of healing. In the cast model, a reduction of the width of $32 \%$ after 3 months, and of $51 \%$ after one year was reported. In these two studies, only measurements in $2 \mathrm{D}$ were used and no implants were installed in the edentulous regions.

Influence of implant installation on the alveolar crest volume: In another clinical study [3], not only 2D, but also 3D measurements were taken. Ten patients received single-tooth rehabilitation by means of implants installed into the alveoli immediately after tooth extraction (immediate implant). High precision impressions were taken before extraction and after 1 year from prosthesis delivering. The total mean volume loss of the alveolar crest was $12.7 \%$, being $5.9 \%$ at the buccal aspect, and $6.8 \%$ at the lingual aspect. These data offered a more rational idea of the amount of volume loss compared to $2 \mathrm{D}$ data and may indicate a lower resorption compared to the previous $2 \mathrm{D}$ studies. However, it has to be considered that implant-abutment-crown units contribute in increasing the volume of the region compared to an edentulous region.

Position of the implant in the extraction socket: Another important aspect that should be considered for immediate implants is the depth of installation and the position of the implant within the extraction sockets in a buccal/lingual plane. Two experiments were carried out in dogs to provide an answer to this issue. In one experiment, the implants were placed either in the center of the alveolus with the margin at the level of the bone crest (control site) or in a lingual position and deeper (test sites) [4]. The histological analysis revealed a higher exposure of the implant surface in the buccal aspect at the control compared to the test sites. Similar results were obtained in an analogous experiment in which the implants were placed either buccally or lingually [5]. This, in turn, means that the more an implant is placed buccally, the more the buccal surface of the implant will be exposed above the bone crest. This may result in poor esthetic outcomes and recession of the peri-implant soft tissues [6].

Buccal gap dimensions and crest width: When an implant is placed lingually into an extraction socket, the formation of a buccal gap is expected. The consequent question is about the influence of this gap on healing and a possible treatment of this defect using a bone filler and/or a membrane to cover the region. In a clinical study on immediate implants, neither bone fillers nor membranes were used [7]. The data from that analysis were stratified based on the horizontal width of the gap at the time of installation [8]. It was shown that horizontal gaps $\leq 1 \mathrm{~mm}$ had higher horizontal $(43 \%)$ and vertical $(-1.4 \mathrm{~mm})$ buccal resorption compared to gaps $>1 \mathrm{~mm}$ ( $32 \%$ and $-0.7 \mathrm{~mm}$, respectively). Another important aspect that was considered in that analysis was the influence on the healing of the width of the buccal bone, measured 1 $\mathrm{mm}$ below the top of the bone crest [8]. Those data were also stratified based on the buccal bone crests width at the time of implant installation. It was shown that buccal bone crests presenting a width $\leq 1 \mathrm{~mm}$ had higher horizontal $(43 \%)$ and vertical $(-1.2 \mathrm{~mm})$ buccal resorption compared to bone crests that presented a width $>1 \mathrm{~mm}(21 \%$ and -0.4 $\mathrm{mm}$, respectively). Considering together the data of horizontal gap and bone width, it appears that the lower are gap and bone width the higher will be the buccal horizontal and vertical resorption after healing. This, in turn, means that the closer is the implant surface to the outer contour of the buccal bone crest the higher will be the resorption. ${ }^{9}$ This corroborate the data from the animal experiments discussed above.

Buccal gap filled with a wider implant: The following question that arise is about the use of a biomaterial to fill the buccal gap aiming

${ }^{\star}$ Correspondence to: Daniele Botticelli, Viale Pascoli 67, 47923 Rimini, Italy, E-mail: daniele.botticelli@gmail.com

Received: June 25, 2018; Accepted: July 02, 2018; Published: July 04, 2018 
to preserve the alveolar crest. A first option to be considered is the use of a larger implant that may fill completely the extraction socket. A couple of experiments in dogs provided a clear answer [10,11]. Implants either with a diameter corresponding to that of the alveoli or with a narrow diameter were installed in the extraction sockets of dogs. Both experiments showed a higher buccal bone resorption at the wider implants compared to the narrow implants. Again, the outcome may be explained by the position of the implant surface in relation to the outer contour of the buccal bone crest that was obviously closer to the wider compared to the narrow implants. These studies also confirmed that a titanium implant is unable to maintain height and width of the buccal bone, as already shown in a clinical study [12].

Buccal gap filled with biomaterial and a collagen membrane:A common treatment of the buccal gaps includes the use of a filler material and/ or a collagen membrane, aiming to preserve the alveolar ridge. It was shown that the use of DBBM (deproteinized bovine bone mineral) might partially prevent a buccal bone resorption, with or without the use of a collagen membrane $[6,13]$. In an experiment in dogs, the gap at immediate implants was either covered with a collagen membrane alone or left without protection [14]. A lower vertical bone resorption was seen at the sites with the membrane.

It was further observed that, when filler materials and collagen membranes are used at immediate implants, the dimensions of the gap might influence the outcomes. In experiments in dogs, DBBM was used as filler material while the control sites were left untreated. Both sites were covered with a collagen membrane [15-17]. It was shown that buccal defects of $\sim 0.6 \mathrm{~mm}(<1 \mathrm{~mm})$ presented better results at the treated compared to the untreated sites [15]. Buccal defects of $\sim 1.7 \mathrm{~mm} \mathrm{(1-2}$ $\mathrm{mm}$ ) presented similar results in both test and control sites [16]. Finally, defects of $\sim 2.3-2.4 \mathrm{~mm}(>2 \mathrm{~mm}$ ) presented better results at the control compared to the treated sites [17]. In this last experiment, residual DBBM granules were seen coronally to the bone crest, embedded into poorly vascularized connective tissue. From these studies, it seems that the wider is the defect the worst is the result at the DBBM sites compared to the untreated sites. It has to be considered that, when DBBM is used in self-contained bone defects, its osteoconductive properties allows the new bone formed from the bone walls to surround the granules and spread towards the central regions of the defect, and eventually fill completely the defect [18]. However, in an extraction socket, the coronal portion of the buccal bone crest will undergo resorption so that, in the coronal region of the alveolus, the self-contained effect will be lost, as well as the source of newly formed bone. This may explain the lack of bone formation and the presence of DBBM granules included into connective tissue in the most coronal region, particles often found by clinicians during surgical re-entries in grafted regions.

Buccal vertical defects: When buccal vertical defects occur after implants installation into extraction sockets, bone fillers and membranes can be used for regenerative purposes, even though spontaneous closure of the defects have been described [19]. The choice of the biomaterial and its properties may influence the outcomes. In an experiment in dogs, buccal standardized vertical defects of $6 \mathrm{~mm}$ in depth were created at the buccal aspect of immediate implants [20]. DBBM or autogenous bone were used at the test and control sites, respectively. A collagen membrane was placed at both sites. After 4 months of healing, a superior coronal and horizontal regeneration was observed at the DBBM sites compared to the autogenous bone sites. The biomaterial granules were found surrounded by new bone while other particles were embedded into connective tissue, especially located on the outer contour of the regenerated bone crest.
Similar buccal defects with a vertical depth of $8 \mathrm{~mm}$ were prepared at immediate implants in dogs [21]. A biomaterial composed of $60 \%$ synthetic HA and 40\% B-TCP was used to fill the defects at the test sites while the defects at the control sites were left untreated. Collagen membranes were placed at both sites. After 4 months of healing, a superior regeneration was obtained at the control sites compared to the test sites. The biomaterial was found integrated into newly formed bone in several biopsies while, in other samples, the granules were surrounded by connective tissue and located outside the regenerated bone crest. The results from these two studies indicate that not all bone substitute may have obtained similar results when used in not selfcontained bone defects.

Presence or absence of neighbor teeth: Another important aspect that should be considered for immediate implants is the presence of the adjacent teeth. In studies in dogs [22,23], in one side of the mandible, the mesial roots of the second, third, fourth premolars and of the first molar were treated endodontically, the teeth were hemisected, and the distal roots were extracted. In the other side of the mandible, all premolars and first molars were extracted. Implants were installed in the distal alveoli at both side of the mandible. After three months of healing, the histological analyses revealed a higher vertical resorption at the implants without adjacent teeth compared to the sites at which the mesial roots, together the corresponding part of the crown, were maintained.

Healing at immediate implants: The healing at immediate implants were also compared with that of implants placed in a standard healed alveolar crest, with or without immediate load [24,25]. After 3 months of healing, no statistically significant differences were found in osseointegration as well as in bone and soft tissues levels, either with or without load. It was concluded that the healing at implants installed in extraction sockets was comparable to those installed in healed sites. During the earliest weeks of healing, due to the presence of a marginal defect, the most coronal contact of the new bone to the implant surface was obviously located more apically at the immediate implants sites compared to the healed sites. It has to be considered that a systematic review with meta-analysis comparing the clinical outcomes of implants installed in fresh extraction socket or in healed sites suggested that immediate implants affects the failure rates of about $1 \%$ more compared to a standard installation in healed sites [26].

Implant stability beyond the apex: Generally, the clinicians try to get primary stability preparing the recipient sites beyond the apex of the alveolus. However, this is not always possible due to the presence of anatomical structures such as the inferior alveolar nerve or the sinus. In an experiment in dogs, the healing at $11 \mathrm{~mm}$ long immediate implants placed in recipient sites prepared beyond the apex was compared with that at $6 \mathrm{~mm}$ long immediate implants that gained the stability within the alveolus, without reaching the apex [27]. Similar osseointegration was obtained at both sites, including in the apical region of the implants.

\section{Conclusion}

In conclusion, several variables may influence the healing at implants installed immediately after tooth extraction. The position and dimensions of the implants in relation of the extraction sockets, the use of alveolar preservation or regenerative techniques, and the presence of neighbor teeth are conditions that will influence the outcome at implants installed immediately after tooth extraction. 


\section{References}

1. Pietrokovski J, Massler M (1967) Alveolar ridge resorption following tooth extraction. J Prosthet Dent 17: 21-27.

2. Schropp L, Wenzel A, Kostopoulos L, Karring T (2003) Bone healing and soft tissue contour changes following single-tooth extraction: a clinical and radiographic 12-month prospective study. Int J Periodontics Restorative Dent 23: 313-23.

3. Szathvary I, Caneva M, Caneva M, Bressan E, Botticelli D, Meneghello R, et al. (2015) A volumetric 3-D digital analysis of dimensional changes to the alveolar process at implants placed immediately into extraction sockets. Journal of Oral Science \& Rehabilitation 1: 62-69.

4. Caneva M, Salata LA, de Souza SS, Baffone G, Lang NP, Botticelli D, et al. (2010) Influence of implant positioning in extraction sockets on osseointegration: histomorphometric analyses in dogs. Clin Oral Implants Res 21: 43-49.

5. De Santis E, Salata LA, Pereira FP, Ferraris S, Pantani F, Botticelli D, et al. (2016) Influence of the position of implants placed immediately into extraction sockets: An experimental study in dogs. J Oral Science Rehabilitation 2: 14-21.

6. Chen ST, Darby IB, Reynolds EC (2007) A prospective clinical study of non-submerged immediate implants: clinical outcomes and esthetic results. Clin Oral Implants Res 18: $552-562$.

7. Sanz M, Cecchinato D, Ferrus J, Pjetursson EB, Lang NP, et al. (2010) A prospective, randomized-controlled clinical trial to evaluate bone preservation using implants with different geometry placed into extraction sockets in the maxilla. Clin Oral Implants Res 21: 13-21.

8. Ferrus J, Cecchinato D, Pjetursson EB, Lang NP, Sanz M, et al. (2010) Factors influencing ridge alterations following immediate implant placement into extraction sockets. Clin Oral Implants Res 21: 22-29.

9. Tomasi C, Sanz M, Cecchinato D, Pjetursson B, Ferrus J, Lang NP, et al. (2010) Bone dimensional variations at implants placed in fresh extraction sockets: a multilevel multivariate analysis. Clin Oral Implants Res 21: 30-36.

10. Caneva M, Salata LA, de Souza SS, Bressan E, Botticelli D, Lang NP, et al. (2010) Hard tissue formation adjacent to implants of various size and configuration immediately placed into extraction sockets: an experimental study in dogs. Clin Oral Implants Res 21: 885-890.

11. Caneva M, Botticelli D, Rossi F, Cardoso LC, Pantani F, Lang NP, et al. (2012) Influence of implants with different sizes and configurations installed immediately into extraction sockets on peri-implant hard and soft tissues: an experimental study in dogs. Clin Oral Implants Res 23: 396-401.

12. Botticelli D, Berglundh T, Lindhe J (2004) Hard-tissue alterations following immediate implant placement in extraction sites. J Clin Periodontol 31: 820-828.

13. Cornelini R, Cangini F, Martuscelli G, Wennström J (2004) Deproteinized bovine bone and biodegradable barrier membranes to support healing following immediate placement of transmucosal implants: a short-term controlled clinical trial. Int $J$ Periodontics Restorative Dent 24: 555-563.

14. Caneva M, Botticelli D, Salata LA, Scombatti Souza SL, Carvalho Cardoso L, Lang NP, et al. (2010) Collagen membranes at immediate implants: a histomorphometric study in dogs. Clin Oral Implants Res 21: 891-897.
15. Caneva M, Botticelli D, Pantani F, Baffone GM, Rangel IG Jr, Lang NP (2012) Deproteinized bovine bone mineral in marginal defects at implants installed immediately into extraction sockets: an experimental study in dogs. Clin Oral Implants Res 23: 106-112.

16. Favero G, Botticelli D, Favero G, García B, Mainetti T, Lang NP (2013) Alveolar bony crest preservation at implants installed immediately after tooth extraction: an experimental study in the dog. Clin Oral Implants Res 24: 7-12.

17. Favero G, Lang NP, De Santis E, Gonzalez BG, Schweikert MT, Botticelli D, et al. (2013) Ridge preservation at implants installed immediately after molar extraction. An experimental study in the dog. Clin Oral Implants Res 24: 255-261.

18. Botticelli D, Berglundh T, Lindhe J (2004) The influence of a biomaterial on the closure of a marginal hard tissue defect adjacent to implants. An experimental study in the dog. Clin Oral Implants Res 15: 285-292.

19. Bressan E, Sivolella S, Stellini E, Almagro Urrutia Z, Lang NP, Botticelli D, et al (2013) Healing of buccal dehiscence defects at implants installed immediately into extraction sockets - an experimental study in dogs. Clin Oral Implants Res 24: 270-277.

20. Pereira FP, De Santis E, Hochuli-Vieira E, de Souza Faco EF, Pantani F, Salata LA, et al. (2016) Deproteinized Bovine Bone Mineral or Autologous Bone at Dehiscence Type Defects at Implants Installed Immediately into Extraction Sockets: An Experimental Study in Dogs. Clin Implant Dent Relat Res18: 507-516.

21. De Santis E, Lang NP, Salata LA, Pereira FP, Favero V, Botticelli D (2016) Healing of BoneCeramic(TM) at buccal dehiscence defects at implants installed immediately into extraction sockets. An experimental study in dogs. Clin Oral Implants Res 27: 1462-1468.

22. Favero G, Lang NP, Favero G, León IG, Salata LA, Botticelli D, et al. (2012) Role of teeth adjacent to implants installed immediately into extraction sockets: an experimental study in the dog. Clin Oral Implants Res 23: 402-408.

23. Favero G, Botticelli D, Rea M, Pantani F, León IG, Lang NP, et al. (2013) Influence of presence or absence of teeth adjacent to implants installed immediately into extraction sockets on peri-implant hard tissue levels: an experimental study in the dog. Clin Oral Implants Res 24: 262-269.

24. Mainetti T, Lang NP, Bengazi F, Sbricoli L, Soto Cantero L, Botticelli D, et al. (2015) Immediate loading of implants installed in a healed alveolar bony ridge or immediately after tooth extraction: an experimental study in dogs. Clin Oral Implants Res 26: 435441

25. Mainetti T, Lang NP, Bengazi F, Favero V, Soto Cantero L, Botticelli D, et al. (2016) Sequential healing at implants installed immediately into extraction sockets. An experimental study in dogs. Clin Oral Implants Res 27: 130-138.

26. Chrcanovic BR, Albrektsson T, Wennerberg A (2015) Dental implants inserted in fresh extraction sockets versus healed sites: a systematic review and meta-analysis. $J$ Dent 43: $16-41$.

27. Bressan E, Sivolella S, Urrutia ZA, Salata LA, Lang NP, Botticelli D, et al. (2012) Short implants $(6 \mathrm{~mm})$ installed immediately into extraction sockets: an experimental study in dogs. Clin Oral Implants Res 23: 536-541.

Copyright: (C2018 Iida T. This is an open-access article distributed under the terms of the Creative Commons Attribution License, which permits unrestricted use, distribution, and reproduction in any medium, provided the original author and source are credited. 